\title{
Definitive chemoradiotherapy in patients with squamous cell cancers of the head and neck - results from an unselected cohort of the clinical cooperation group "Personalized Radiotherapy in Head and Neck Cancer"
}

Lars Schüttrumpf ${ }^{1,2^{*}}$ (D), Sebastian Marschner ${ }^{1,2}$, Katrin Scheu ${ }^{1,3}$, Julia Hess $^{1,3}$, Sibylle Rietzler ${ }^{1,4}$, Axel Walch ${ }^{5}$, Philipp Baumeister ${ }^{1,6}$, Thomas Kirchner $^{1,4}$, Ute Ganswindt ${ }^{1,7}$, Horst Zitzelsberger ${ }^{1,3}$, Claus Belka ${ }^{1,2}$ and Cornelius Maihoefer ${ }^{1,2}$

\begin{abstract}
Background: Definitive chemoradiotherapy (dCRT) is a standard treatment for patients with locally advanced head and neck cancer. There is a clinical need for a stratification of this prognostically heterogeneous group of tumors in order to optimize treatment of individual patients. We retrospectively reviewed all patients with head and neck squamous cell carcinoma (HNSCC) of the oral cavity, oropharynx, hypopharynx, or larynx, treated with dCRT from 09/2008 until 03/2016 at the Department of Radiation Oncology, LMU Munich. Here we report the clinical results of the cohort which represent the basis for biomarker discovery and molecular genetic research within the framework of a clinical cooperation group.
\end{abstract}

Methods: Patient data were collected and analyzed for outcome and treatment failures with regard to previously described and established risk factors.

(Continued on next page)

\footnotetext{
* Correspondence: Radoncmanuscript+schuettrumpf@gmail.com

${ }^{1}$ Clinical Cooperation Group 'Personalized Radiotherapy in Head and Neck

Cancer', Helmholtz Zentrum München, German Research Center for

Environmental Health GmbH, 85764 Neuherberg, Germany

2Department of Radiation Oncology, University Hospital, LMU Munich,

Marchioninistr 15, 81377 Munich, Germany

Full list of author information is available at the end of the article
}

(C) The Author(s). 2020 Open Access This article is distributed under the terms of the Creative Commons Attribution 4.0 International License (http://creativecommons.org/licenses/by/4.0/), which permits unrestricted use, distribution, and reproduction in any medium, provided you give appropriate credit to the original author(s) and the source, provide a link to the Creative Commons license, and indicate if changes were made. The Creative Commons Public Domain Dedication waiver (http://creativecommons.org/publicdomain/zero/1.0/) applies to the data made available in this article, unless otherwise stated. 
(Continued from previous page)

Results: We identified 184 patients with a median follow-up of 65 months and a median age of 64 years. Patients received dCRT with a median dose of $70 \mathrm{~Gy}$ and simultaneous chemotherapy in $90.2 \%$ of cases, mostly mitomycin C / 5-FU in concordance with the ARO 95-06 trial. The actuarial 3-year overall survival (OS), local, locoregional and distant failure rates were 42.7, 29.8, 34.0 and 23.4\%, respectively. Human papillomavirus-associated oropharynx cancer (HPVOPC) and smaller gross tumor volume were associated with significantly improved locoregional tumor control rate, disease-free survival (DFS) and OS in multivariate analysis. Additionally, lower hemoglobin levels were significantly associated with impaired DFS und OS in univariate analysis. The extent of lymph node involvement was associated with distant failure, DFS and OS. Moreover, 92 patients (50\%) of our cohort have been treated in concordance with the ARO 95-06 study, corroborating the results of this study.

Conclusion: Our cohort is a large unselected monocentric cohort of HNSCC patients treated with dCRT. Tumor control rates and survival rates compare favorably with the results of previously published reports. The clinical data, together with the available tumor samples from biopsies, will allow translational research based on molecular genetic analyses.

Keywords: Head and neck cancer, Defintive, Primary, Chemoradiation, Radiotherapy, HNSCC, HPV

\section{Introduction}

Head and Neck Cancer is the seventh most common type of cancer in the world. In Europe, Head and Neck Cancer accounts for an estimated 145,000 new cases every year [1]. Definitive chemoradiotherapy (dCRT) is a standard-of-care treatment for locoregional advanced head and neck squamous cell cancer (HNSCC). A simultaneous treatment by chemotherapy and radiotherapy turned out to be the most effective option and leads to an improvement of the overall survival (OS) of around $5 \%$ [2]. The prognosis of the patients varies depending on risk factors such as tumor localization, the size of the primary tumor, the extent of the lymph node involvement and tumor hypoxia [3]. Moreover, in recent years, the identification of human papillomavirus-associated tumorigenesis in oropharyngeal cancer (HPVOPC) has proven to be one of the most important prognostic factors [4]. Avoidable major risk factors include smoking and alcohol abuse. Smokers are ten times more likely to develop HNSCC than non-smokers [5]. Depending on the tumor biology and the risk factors mentioned, HNSCC vary widely in response to therapy and prognosis for the patient [6-9].

Further research is still crucial to establish biomarkers enabling a tailored, risk-adapted use of the available treatment modalities. To achieve this goal, a solid database of a HNSCC cohort is necessary for our translational research in the framework of the multidisciplinary translational Clinical Cooperation Group 'Personalized Radiotherapy in Head and Neck Cancer'.

\section{Material \& Methods}

We retrospectively analyzed patients with squamous cell carcinoma of the oral cavity, oropharynx, hypopharynx and larynx who have been treated with dCRT in our clinic (Department of Radiation Oncology, LudwigMaximilians-University Munich - LMU) between 09/ 2008 until 03/2016.

Until 2013 CT-based three-dimensional planning was used to generate radiation plans with a sequential boost for therapeutic planning target volume (PTV) prescribing a median dose of $50 \mathrm{~Gy}$ for prophylactic lymph node level, 60 Gy for involved lymph node level and 70 Gy for therapeutic target volume (primary tumor and suspicious lymph nodes). Patients were treated 5 days a week with 2 Gy per fraction. Since 2013 patients were treated by a simultaneous integrated boost (SIB) using IMRT / VMAT [10]. A median dose of 70 Gy $(66 / 69.96 / 70 / 70.4)$ was prescribed to the therapeutic target volume in 32-35 fractions of 2 to $2.2 \mathrm{~Gy}$. A median dose of 50.4 to $54.45 \mathrm{~Gy}$ was prescribed to the prophylactic lymph node levels.

Most patients received additional chemotherapy. Department standard was Mitomycin C / 5-FU in concordance with ARO 95-06 (Mitomycin $C$ was administered as a single intravenous bolus injection of $10 \mathrm{mg} / \mathrm{m}^{2}$ on days 5 and 36, 5-FU was administered as a continuous infusion for $120 \mathrm{~h}$ at $600 \mathrm{mg} / \mathrm{m}^{2} / \mathrm{d}$ on days 1 to 5 ).

This standard was changed to CDDP weekly in 2013 $\left(40 \mathrm{mg} /{ }^{2}\right.$ on day $\left.2,8,15,22,29,36,43\right)$. Other chemotherapeutic regimens (such as Carboplatin, Mitomycin C mono or Cetuximab) were used if a patient was not suitable for department standard. Due to comorbidities and reduced general condition, some patients were treated with radiotherapy alone.

The clinic's radiation therapy management system (Mosaiq ${ }^{\bullet}$ - Elekta, Sweden) and patient files recorded in a dedicated Microsoft Access Relational Database were used to collect patient data.

Tumor stage was assessed using the UICC 2010 TNM classification, if not stated otherwise. Immunohistochemical 
(IHC) p16INK4a staining results from our local pathology was used as a surrogate marker for HPV-infection, if available (75 patients). Additionally, $81 \mathrm{HNSCC}$ patients were analyzed for HPV p16 within the framework of the KKG. IHC p16INK4a staining was performed using the CINtec TM Histology Kit (Roche mtm laboratories AG, Germany) on a Ventana Benchmark LT automated immunostainer (Ventana Medical Systems, Tucson AZ, USA) according to the protocol. Strong and diffuse nuclear and cytoplasmic staining in $>70 \%$ of tumor cells were considered as p16-positive.

Follow-up data has been collected in the joint survivorship clinic of the Otorhinolaryngological and the Radiation Oncology Department of the LMU, but also from follow-up visits in our clinic or by phone interviews.

Follow-up has been calculated from the last day of radiation therapy with the inverse Kaplan-Meier method. All other endpoints such as survival or time to recurrence have been calculated from the first day of the radiation treatment. The events of the survival endpoints were defined as following: OS - death, DFS - death or any recurrence, DSS - only death related to recurring HNSCC. $P$-values were determined using log-rank testing for comparison between groups. Univariate and multivariate analyses were conducted using Cox proportional hazard regression models. If more than one factor was significant in univariate Cox regression analysis, multivariate Cox regression analysis was used for determining the influence of multiple covariates. Statistical analyses were performed with SPSS V25 (IBM, Chicago, IL). $P$-values of $<0.05$ were considered statistically significant. Median estimates and Hazard ratios (HR) with 95\% confidence intervals (CI) were determined. Ethics approval for collecting patient-derived data and investigating tumor samples by molecular genetic approaches were granted by the local ethics committee of the LMU Munich (No. 448-13, 459-13, 17-116).

\section{Results}

\section{Patient and treatment characteristics}

A total of 184 patients with HNSCC of the oral cavity, oropharynx, hypopharynx and larynx were treated with dCRT at the Department of Radiation Oncology of the LMU between 09/2008 until 03/2016. Patient, tumor and treatment characteristics are shown in Table 1. The median age was 64 years (range 23-89 years) at time of diagnosis. The median follow-up was 65.0 months. $97 \%$ of patients completed radiation therapy and received at least 66 Gy to primary tumor. Median cumulative dose was $70 \mathrm{~Gy}$. Nine patients (4.9\%) were treated with hyperfractionated accelerated radiotherapy. $90.2 \%$ of patients $(n=166)$ received concurrent systemic therapy.
Tumor control rates and survival data for all patients For all patients 2-, 3- and 5-year actuarial survival rates were $55.7,42.7$ and $30.3 \%$ for overall survival (OS), 44.0, 33.8 and $24.2 \%$ for disease-free survival rates (DFS) and $73.3,65.2$ and $58.5 \%$ for disease-specific survival (DSS), respectively (Fig. 1a). The actuarial 1-, 2- and 3-year failure rates were 15.5, 23.8 and $29.8 \%$ for local, 20.0, 28.3 and $34.0 \%$ for locoregional, 15.0, 22.2 and 23.4\% (last event occurred at 30 months) for distant and 23.7, 37.9 and $44.1 \%$ for all failures (Fig. 1b).

\section{Tumor control rates and survival data for the ARO 95-06 subgroup}

Ninety-two patients were treated with $\mathrm{MMC} / 5-\mathrm{FU}$ in concordance to the chemotherapy arm of the ARO 9506 study, albeit with normofractionation. The median age was 61 years (23-78 years) at time of diagnosis. The median follow-up was 70 months (see Table 1). 91\% of patients received complete courses of chemotherapy; the remaining patients did not receive both cycles due to various reasons (worsening condition, refusal, cytopenia, reaction to chemotherapy). All in all, the ARO 95-06 chemotherapy regimen was well tolerated. The estimated 3-year OS, DFS and DSS were 50.6, 42.8 and 69.2\%, respectively (Fig. 1c). The estimated $3 \mathrm{yr}$ local, locoregional and distant failure rates were 30.0, 32.4 and 22.1\%, respectively (Fig. 1d). HPV-p16-status was associated with a significantly improved locoregional control, DFS and OS in the ARO-analogue group. Compared to platinumbased chemotherapy regime no difference was found in locoregional or distant control and for DFS or OS.

\section{Stratification according to risk factors}

While the size of primary tumor (using T-stage) predicted for local recurrence only, the extent of lymph node involvement had an impact on distant metastasis rate, DFS and OS (Fig. 2). By analyzing primary tumor size using the gross tumor volume (GTVp) as continuous variable for cox regression modeling, the probability of a local relapse following dCRT increased by $4 \%$ per $10 \mathrm{cc}$ absolute tumor volume. DFS and OS decreased by $3 \%$ per $10 \mathrm{cc}$ in uni- and multivariate analysis (Table 2).

Lower hemoglobin levels were significantly associated with impaired DFS und OS with a hazard ratio of 0.90 $(p=0.024)$ und $0.88(p=0.009)$ per $\mathrm{g} / \mathrm{dl}$.

With regard to the clinical endpoints there were no significant differences depending on the smoking status.

\section{HPV- p16 positive oropharyngeal carcinoma (HPVOPC)}

The 3-year OS, DFS and DSS rates of HPVOPC with 65.8, 56.0 and 95.0\% (last events at 35, 27 and 16 months) were significantly higher compared to $37.9,30.2$ and $60.7 \%$ of patients with non-HPVOPC, respectively (Fig. 3). Patients with HPVOPC also had significantly 
Table 1 Patient and treatment characteristics for all patients (left panel), ARO-analogue subgroup (middle panel) and HPVOPC (right panel)

\begin{tabular}{|c|c|c|c|c|c|c|}
\hline \multirow[t]{3}{*}{ Factors } & \multirow{2}{*}{\multicolumn{2}{|c|}{$\begin{array}{l}\text { All patients } \\
n=184\end{array}$}} & \multirow{2}{*}{\multicolumn{2}{|c|}{$\begin{array}{l}\text { ARO-analogue } \\
n=92\end{array}$}} & \multirow{2}{*}{\multicolumn{2}{|c|}{$\begin{array}{l}\text { HPVOPC } \\
n=25\end{array}$}} \\
\hline & & & & & & \\
\hline & Number & Percent & Number & Percent & Number & Percent \\
\hline \multicolumn{7}{|l|}{ Age } \\
\hline$<45$ & 4 & 2.2 & 3 & 3.3 & 1 & 4.0 \\
\hline $45-54$ & 30 & 16.3 & 23 & 25.0 & 1 & 4.0 \\
\hline $55-64$ & 66 & 35.7 & 37 & 40.2 & 8 & 32.0 \\
\hline $65-74$ & 53 & 28.8 & 23 & 25.0 & 9 & 36.0 \\
\hline $75-84$ & 27 & 14.7 & 6 & 6.5 & 6 & 24.0 \\
\hline$>85$ & 4 & 2.2 & 0 & 0.0 & 0 & 0.0 \\
\hline \multicolumn{7}{|l|}{ Sex } \\
\hline male & 143 & 77.7 & 71 & 77.2 & 20 & 80.0 \\
\hline female & 41 & 22.3 & 21 & 22.8 & 5 & 20.0 \\
\hline \multicolumn{7}{|l|}{ Diagnosis class } \\
\hline first diagnosis & 161 & 87.5 & 83 & 89.2 & 22 & 88.0 \\
\hline disease recurrence & 23 & 12.5 & 9 & 9.8 & 3 & 12.0 \\
\hline \multicolumn{7}{|l|}{ Localization } \\
\hline Oropharynx & 78 & 42.4 & 40 & 43.5 & 25 & 100.0 \\
\hline Larynx & 37 & 20.1 & 17 & 18.5 & 0 & 0.0 \\
\hline Hypopharynx & 35 & 19 & 20 & 21.7 & 0 & 0.0 \\
\hline Oral cavity & 34 & 18.5 & 15 & 16.3 & 0 & 0.0 \\
\hline \multicolumn{7}{|l|}{ Primary Tumor (T) } \\
\hline $\mathrm{cT} 1-2$ & 37 & 20.1 & 13 & 14.1 & 3 & 12.0 \\
\hline CT3-4 & 147 & 79.9 & 79 & 85.9 & 22 & 88.0 \\
\hline \multicolumn{7}{|l|}{ Lymph Nodes (N) } \\
\hline cNO-cN2a & 72 & 39.1 & 35 & 38.0 & 8 & 32.0 \\
\hline $\mathrm{cN} 2 \mathrm{~b}-\mathrm{cN} 2 \mathrm{c}$ & 105 & 57.1 & 53 & 57.6 & 17 & 68.0 \\
\hline $\mathrm{cN} 3$ & 7 & 3.8 & 4 & 4.3 & 0 & 0.0 \\
\hline \multicolumn{7}{|l|}{ Metastasis (M) } \\
\hline $\mathrm{CMO}$ & 184 & 100.0 & 92 & 100.0 & 25 & 100.0 \\
\hline CM1 & 0 & 0.0 & 0 & 0.0 & 0 & 0.0 \\
\hline \multicolumn{7}{|c|}{ Stage 7 th edition (8th edition HPVOPC ${ }^{\text {a }}$ ) } \\
\hline UICC I & 1 & 0.5 & 1 & 1.1 & $0\left(2^{\mathrm{a}}\right)$ & $0.0\left(8.0^{\mathrm{a}}\right)$ \\
\hline UICC $\|$ & 8 & 4.3 & 5 & 5.4 & $1\left(10^{\mathrm{a}}\right)$ & $4.0\left(40.0^{\mathrm{a}}\right)$ \\
\hline UICC III & 30 & 16.3 & 15 & 16.3 & $4\left(13^{a}\right)$ & $16.0\left(52.0^{\mathrm{a}}\right)$ \\
\hline UICC IV & 145 & 78.8 & 71 & 77.2 & $20\left(0^{\mathrm{a}}\right)$ & $80.0\left(0.0^{\mathrm{a}}\right)$ \\
\hline \multicolumn{7}{|l|}{ Grading } \\
\hline G1 & 7 & 3.8 & 3 & 3.3 & 0 & 0 \\
\hline G2 & 89 & 48.8 & 43 & 46.7 & 9 & 36.0 \\
\hline G3 & 83 & 45.8 & 45 & 48.9 & 16 & 64.0 \\
\hline Gx & 5 & 2.7 & 1 & 1.1 & 0 & 0 \\
\hline \multicolumn{7}{|l|}{ p16 staining } \\
\hline Positive & 35 & 19.0 & 21 & 22.8 & 25 & 100.0 \\
\hline Negative & 121 & 65.8 & 59 & 64.1 & 0 & 0.0 \\
\hline unknown & 28 & 15.2 & 12 & 13.0 & 0 & 0.0 \\
\hline
\end{tabular}


Table 1 Patient and treatment characteristics for all patients (left panel), ARO-analogue subgroup (middle panel) and HPVOPC (right panel) (Continued)

\begin{tabular}{|c|c|c|c|c|c|c|}
\hline \multirow[t]{3}{*}{ Factors } & \multirow{2}{*}{\multicolumn{2}{|c|}{$\begin{array}{l}\text { All patients } \\
n=184\end{array}$}} & \multirow{2}{*}{\multicolumn{2}{|c|}{$\begin{array}{l}\text { ARO-analogue } \\
n=92\end{array}$}} & \multirow{2}{*}{\multicolumn{2}{|c|}{$\begin{array}{l}\text { HPVOPC } \\
n=25\end{array}$}} \\
\hline & & & & & & \\
\hline & Number & Percent & Number & Percent & Number & Percent \\
\hline \multicolumn{7}{|l|}{ smoking history } \\
\hline$<10$ pack-years & 10 & 5.4 & 3 & 3.3 & 2 & 8.0 \\
\hline$>10$ pack-years & 99 & 53.8 & 49 & 53.3 & 7 & 28.0 \\
\hline unknown & 75 & 40.8 & 40 & 43.5 & 16 & 64.0 \\
\hline \multicolumn{7}{|l|}{ Therapeutic Dose } \\
\hline Median & $70 \mathrm{~Gy}$ & & 70 Gy & & 70 Gy & \\
\hline$>=66 \mathrm{~Gy}$ & 179 & 97.3 & 90 & 97.8 & 25 & 100.0 \\
\hline$<66 \mathrm{~Gy}$ & 5 & 2.7 & 2 & 2.2 & 0 & 0.0 \\
\hline \multicolumn{7}{|l|}{ GTV volume } \\
\hline available & 174 & 94.6 & 87 & 94.6 & 24 & 96.0 \\
\hline missing & 10 & 5.4 & 5 & 5.4 & 1 & 4.0 \\
\hline range (in cc) & $2-789$ & & $2-789$ & & 18-359 & \\
\hline mean (in cc) & 61 & & 106 & & 107 & \\
\hline \multicolumn{7}{|l|}{ Chemotherapy } \\
\hline no & 18 & 9.8 & 0 & 0.0 & 1 & 4.0 \\
\hline yes & 166 & 90.2 & 92 & 100.0 & 24 & 96.0 \\
\hline MMC / 5FU & 92 & 50 & 92 & 100.0 & 18 & 72.0 \\
\hline MMC mono & 28 & 15.2 & 0 & 0.0 & 2 & 8.0 \\
\hline Platin based & 26 & 14.1 & 0 & 0.0 & 1 & 4.0 \\
\hline Cetuximab mono & 20 & 10.9 & 0 & 0.0 & 3 & 12.0 \\
\hline Chemo completed & 135 & 81.3 & 84 & 91.3 & 20 & 83.3 \\
\hline Chemo stopped & 31 & 18.7 & 8 & 8.7 & 4 & 16.7 \\
\hline patient refused & 1 & & 1 & & 0 & \\
\hline worsening condition & 15 & & 5 & & 4 & \\
\hline cytopenia & 9 & & 1 & & 0 & \\
\hline reaction to chemo & 6 & & 1 & & 0 & \\
\hline \multicolumn{7}{|l|}{ Causes of death } \\
\hline tumor related & 50 & & 27 & & 1 & \\
\hline comorbidities & 40 & & 21 & & 6 & \\
\hline therapy-associated & 0 & & 0 & & 0 & \\
\hline second primary & 11 & & 5 & & 0 & \\
\hline unknown & 12 & & 5 & & 1 & \\
\hline
\end{tabular}

${ }^{\text {a }}$ The UICC 8th edition stage is shown in parenthesis (HPVOPC only)

less local and locoregional recurrences in univariate $(\mathrm{HR}=0.22$ and $0.18, p$-values $<0.05)$ and multivariate analysis $(\mathrm{HR}=0.21$ and $0.18, p$-values $<0.05)$. For distant failure no significant difference was found. No locoregional recurrence occurred in patients with stage I + II HPVOPC (UICC TNM 8th edition), although accounting for $48.0 \%$ of all 25 patients. Additionally, only one out of five distant failures was observed in stage I + II (8th edition) patients. For patients with HPVOPC, smoking status is known in 9 out of 25 patients only. Two of the nine patients have less than 10 pack-years and therefore meet the inclusion criteria of de-escalation studies which exclude all heavy smokers with HPVOPC. Due to the small number of cases in this subgroup, no separate analysis could be performed.

\section{Discussion}

The present study represents a well-established and closely monitored unselected cohort of 184 "everyday 


\section{all patients}

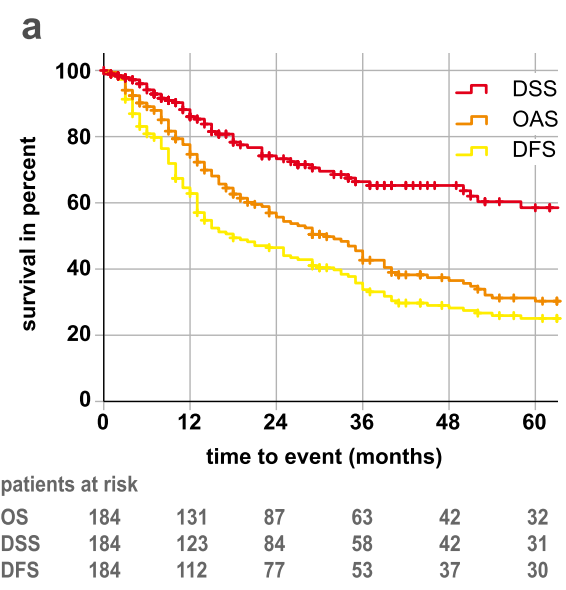

\section{ARO 95-06 analogue subgroup}

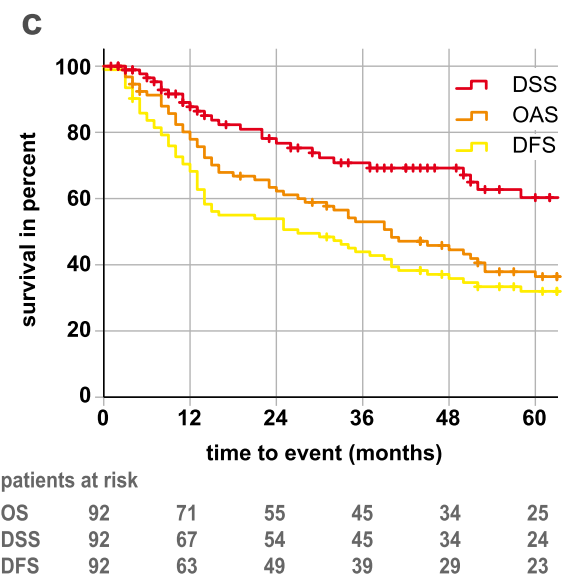

b

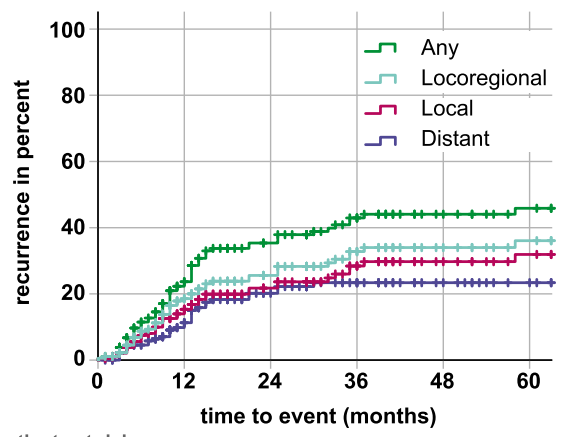

patients at risk

$\begin{array}{lllllll}\text { local } & 184 & 120 & 82 & 56 & 38 & 31 \\ \text { locoreg. } & 184 & 115 & 82 & 56 & 38 & 31 \\ \text { distant } & 184 & 122 & 79 & 57 & 40 & 31 \\ \text { any } & 184 & 112 & 77 & 53 & 37 & 30\end{array}$

\section{d}

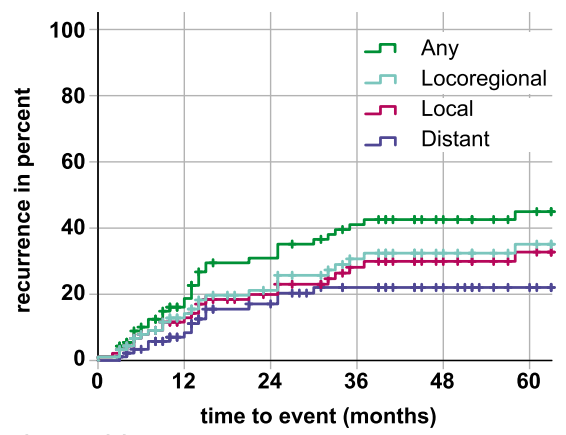

patients at risk

$\begin{array}{lllllll}\text { local } & 92 & 65 & 52 & 40 & 30 & 24 \\ \text { locoreg. } 92 & 64 & 52 & 40 & 30 & 24 \\ \text { distant } & 92 & 67 & 51 & 42 & 32 & 24\end{array}$

Fig. 1 Kaplan-Meier plots a overall survival (OS), disease-free survival (DFS) and disease-specific survival (DSS) of all patients b local, locoregional, distant and any failure rates of all patients. c overall survival (OS), disease-free survival (DFS) and disease-specific survival (DSS) of the AROanalogue subgroup $\mathbf{d}$ local, locoregional, distant and any failure rates of the ARO-analogue subgroup. Follow-up time was clipped at 60 months. Patients at risk are displayed under the respective plots. Censors are represented by crosses

patients" who were treated with definitive CRT between 09/2008 until 03/2016 in our department with tumors of the oral cavity, oropharynx, hypopharynx and larynx. Since a combined treatment by chemotherapy and radiotherapy has shown a survival benefit in many prospective studies, simultaneous CRT has become the therapeutic standard for patients with HNSCC. Depending on tumor localization the absolute survival advantage is between four to $9 \%$ [2]. Beyond that, additional induction chemotherapy prior to concurrent CRT or acceleration of radiotherapy did not improve outcome [11-13].

The results of our patients compare favorably with previously published multicentric cohorts such as GORTEC trial [12], Head and Neck Intergroup trial [14] and ARO 95-06 trial [15].
Exemplarily, the reported 3-year overall survival was between 37 and $43 \%$ compared to $42.7 \%$ in our cohort. Our institutional chemotherapy regime for dCRT at that time was derived from the ARO 95-06 trial [16]. However, since the hyperfractionated accelerated radiation therapy used in the ARO trial in combination with chemotherapy did not have a survival advantage compared to normofractionation in other studies, we mainly treated patients with 70Gy (2 Gy per fraction, 5 fractions a week) plus mitomycin C (MMC) and 5-FU [12]. Radiotherapy with MMC/5-FU was well tolerated and fully applied in 84 out of 92 patients (91.2\%). With the limitation of the small number of patients in this study and without any difference between MMC-based and platin-based chemotherapy for all endpoints, MMC/5FU could at least be considered as an alternative 

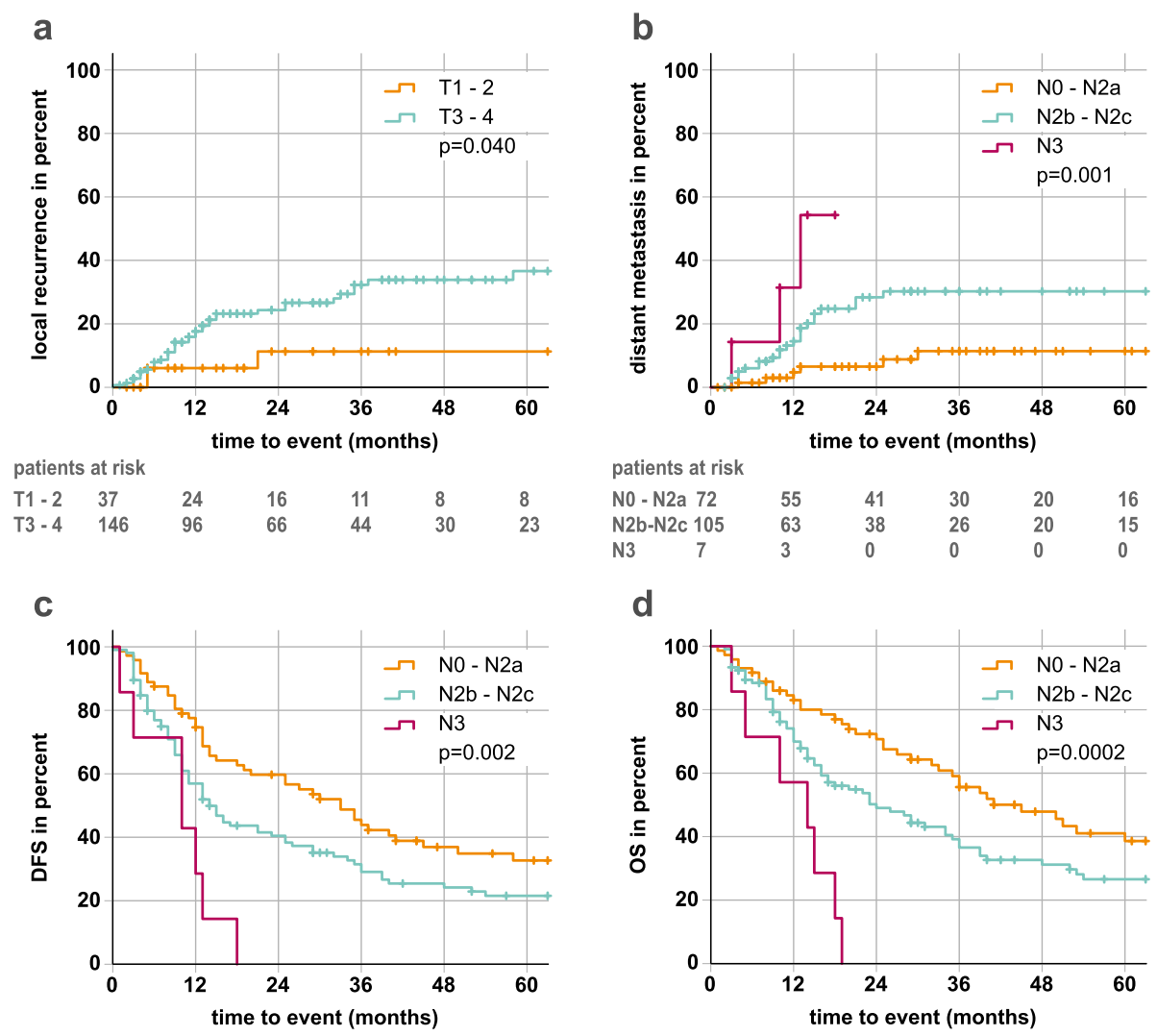

d

$\begin{array}{llllll}\text { N0 }- \text { N2a } 72 & 52 & 39 & 27 & 18 & 15 \\ \text { N2b-N2c 105 } & 57 & 38 & 25 & 19 & 15 \\ \text { N3 } \quad 7 & 2 & 0 & 0 & 0 & 0\end{array}$

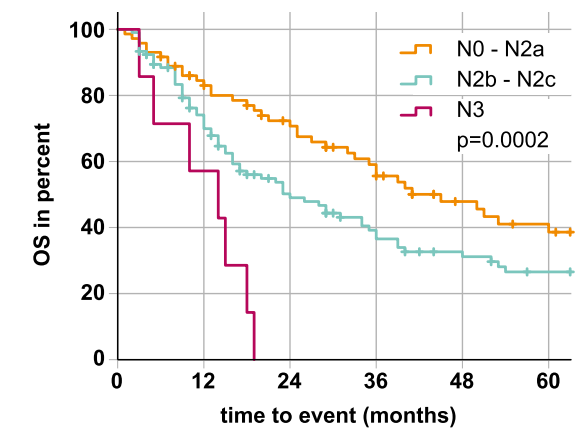

patients at risk

NO - N2a 72

N2b-N2c 105

$\begin{array}{lllll}56 & 44 & 33 & 22 & 16 \\ 70 & 42 & 29 & 21 & 16\end{array}$

Fig. 2 Exemplary Kaplan-Meier plots for clinical risk factors. a local recurrence and primary tumor size (T1-2 vs T3-4) b distant metastasis, c disease free survival, $\mathbf{d}$ overall survival and lymph node status (N0-N2a vs N2b-N2c vs N3). P-values (log rank) of the Kaplan-Meier estimates are shown. Follow-up time was clipped at 60 months. Patients at risk are displayed under the respective plots. Censors are represented by crosses

therapeutic option. However, in the published literature cisplatin is reported as the standard treatment for a simultaneous monotherapy with the strongest effect [17, 18]. The clinical results of our ARO-analog subgroup and the ARO 95-06 trial were comparable with a 5-year PFS of $30.4 \%$ versus $29.3 \%$ and a 5 -year OS of $36.4 \%$ versus $28.6 \%$.

A categorical comparison of $T$-stage $1 / 2$ versus $3 / 4$ showed a significant difference with respect to local recurrences (3 years local control: $88.7 \%$ vs. 66.1\%). However, this improved local control does not result in an improved DFS or OS. GTV volume, on the other hand, allowed a more detailed analysis of local tumor extension and showed a significant decrease for local and locoregional control by $4 \%$ per $10 \mathrm{ml}$ tumor volume each and for DFS and OS by $3 \%$ per $10 \mathrm{ml}$ tumor volume each.

Interestingly, these findings are only partially in line with a recently published paper where GTV primary tumor was only a significant independent prognostic factor for OS in p16-negative tumors but without influence on locoregional control and DFS [19].
An extended lymph node involvement ( $>=\mathrm{N} 2 \mathrm{c}$ ) was associated with an increased risk for distant metastases ( $\mathrm{HR}=2.85, p=0.003)$. This influence was also evident for OS, DFS and DSS $(\mathrm{HR}=1.82,1.65$ and 2.57, $p$ values $<0.05)$ in univariate analysis, but remained significant only for DSS in multivariate analysis $(\mathrm{HR}=2.23$, $p=0.018$ ). This effect may be explained by deaths from comorbidities. The results were consistent with other studies that have shown the predictive value of lymph node involvement on distant metastasis in head and neck cancer [20-22].

Additionally, the measured hemoglobin levels before radiotherapy were associated with survival. For each reduced hemoglobin unit (in $\mathrm{g} / \mathrm{dl}$ ) the DFS and OS decreased by a hazard ratio of 1.11 and $1.14(p=0.024$ and $p=0.009)$. Anemia is common among HNSCC patients. The hemoglobin levels for 15 women and 65 men were below 12 and $13 \mathrm{~g} / \mathrm{dl}$, respectively, resulting in anemia rates of 45.5 and $36.6 \%$. Anemic conditions before treatment may be attributed to the disease itself, impaired dietary intake and comorbid conditions of HNSCC 
Table 2 Univariate and multivariate cox regression analysis on local, locoregional, distant and overall failure rates and overall (OS), disease-specific (DSS) and disease-free (DFS) survival rates; HPV positive oropharyngeal carcinoma (HPVOPC) and lymph node status ( $>=$ N2c) were tested as categorial variables. Gross tumor volume (GTV in cubic centimetres) and Hemoglobine (in g/dl) were tested as continuous variables

\begin{tabular}{|c|c|c|c|c|c|c|}
\hline & \multicolumn{3}{|c|}{ Univariate } & \multicolumn{3}{|c|}{ Multivariate } \\
\hline & $\mathrm{HR}$ & $95 \% \mathrm{Cl}$ & $p$-value & $\mathrm{HR}$ & $95 \% \mathrm{Cl}$ & $p$-value \\
\hline \multicolumn{7}{|l|}{ Local failure (LF) } \\
\hline HPVOPC & 0.22 & $0.05-0.90$ & $0.035^{*}$ & 0.21 & $0.05-0.89$ & $0.035^{*}$ \\
\hline GTV (continuous per $10 \mathrm{cc}$ ) & 1.04 & $1.02-1.07$ & $0.0004^{*}$ & 1.04 & $1.02-1.07$ & $0.0004^{*}$ \\
\hline$>=\mathrm{N} 2 \mathrm{C}$ & 1.36 & $0.72-2.55$ & 0.342 & - & - & - \\
\hline Hemoglobine (continuous per g/dl) & 0.87 & $0.74-1.02$ & 0.082 & - & - & - \\
\hline \multicolumn{7}{|l|}{ Locoregional failure (LRF) } \\
\hline HPVOPC & 0.18 & $0.44-0.76$ & $0.019^{*}$ & 0.18 & $0.04-0.73$ & $0.017^{*}$ \\
\hline GTVp (continuous per $10 \mathrm{cc}$ ) & 1.04 & $1.02-1.07$ & $0.001^{*}$ & 1.04 & $1.02-1.07$ & $0.001^{*}$ \\
\hline$>=\mathrm{N} 2 \mathrm{C}$ & 1.52 & $0.86-2.17$ & 0.150 & - & - & - \\
\hline Hemoglobine (continuous per $\mathrm{g} / \mathrm{dl}$ ) & 0.86 & $0.74-1.001$ & 0.052 & - & - & - \\
\hline \multicolumn{7}{|l|}{ Distant failure (DF) } \\
\hline HPVOPC & 1.15 & $0.43-3.07$ & 0.787 & - & - & - \\
\hline GTV (continuous per $10 \mathrm{cc}$ ) & 1.01 & $0.97-1.05$ & 0.590 & - & - & - \\
\hline$>=\mathrm{N} 2 \mathrm{C}$ & 2.85 & $1.42-5.74$ & $0.003^{*}$ & - & - & - \\
\hline Hemoglobine (continuous per g/dl) & 0.95 & $0.79-1.14$ & 0.549 & - & - & - \\
\hline \multicolumn{7}{|l|}{ Any failure (AF) } \\
\hline HPVOPC & 0.39 & $0.16-0.99$ & $0.047^{*}$ & 0.37 & $0.15-0.94$ & $0.037^{*}$ \\
\hline GTV (continuous per $10 \mathrm{cc}$ ) & 1.04 & $1.01-1.06$ & $0.001^{*}$ & 1.03 & $1.01-1.05$ & $0.018^{*}$ \\
\hline$>=\mathrm{N} 2 \mathrm{C}$ & 1.95 & $1.20-3.18$ & $0.007^{*}$ & 1.90 & $1.07-3.37$ & $0.029^{*}$ \\
\hline Hemoglobine (continuous per $\mathrm{g} / \mathrm{dl}$ ) & 0.89 & $0.77-1.02$ & 0.090 & - & - & - \\
\hline \multicolumn{7}{|l|}{ Overall survival (OAS) } \\
\hline HPVOPC & 0.30 & $0.15-0.63$ & $0.001^{*}$ & 0.27 & $0.12-0.59$ & $0.001^{*}$ \\
\hline GTV (continuous per $10 \mathrm{cc}$ ) & 1.03 & $1.02-1.05$ & $0.0001^{*}$ & 1.03 & $1.01-1.04$ & $0.010^{*}$ \\
\hline$>=\mathrm{N} 2 \mathrm{C}$ & 1.82 & $1.25-2.65$ & $0.002^{*}$ & 1.48 & $0.96-2.27$ & 0.073 \\
\hline Hemoglobine (continuous per $\mathrm{g} / \mathrm{dl}$ ) & 0.88 & $0.80-0.97$ & $0.009^{*}$ & 0.95 & $0.85-1.06$ & 0.335 \\
\hline \multicolumn{7}{|l|}{ Disease specific survival (DSS) } \\
\hline HPVOPC & 0.09 & $0.01-0.63$ & $0.016^{*}$ & 0.09 & $0.01-0.69$ & $0.020^{*}$ \\
\hline GTV (continuous per $10 \mathrm{cc}$ ) & 1.04 & $1.02-1.07$ & $0.0003^{*}$ & 1.03 & $1.004-1.06$ & $0.027^{*}$ \\
\hline$>=\mathrm{N} 2 \mathrm{C}$ & 2.57 & $1.47-4.49$ & $0.001^{*}$ & 2.23 & $1.15-4.34$ & $0.018^{*}$ \\
\hline Hemoglobine (continuous per g/dl) & 0.84 & $0.73-0.98$ & $0.023^{*}$ & 0.91 & $0.76-1.08$ & 0.268 \\
\hline \multicolumn{7}{|l|}{ Disease free survival (DFS) } \\
\hline HPVOPC & 0.38 & $0.20-0.71$ & $0.003^{*}$ & 0.37 & $0.19-0.71$ & $0.003^{*}$ \\
\hline GTV (continuous per $10 \mathrm{cc}$ ) & 1.03 & $1.02-1.05$ & $0.00006^{*}$ & 1.03 & $1.01-1.05$ & $0.004^{*}$ \\
\hline$>=\mathrm{N} 2 \mathrm{C}$ & 1.65 & $1.16-2.34$ & $0.006^{*}$ & 1.49 & $0.99-2.24$ & 0.056 \\
\hline Hemoglobine (continuous per $\mathrm{g} / \mathrm{dl}$ ) & 0.90 & $0.82-0.97$ & $0.024^{*}$ & 0.96 & $0.87-1.07$ & 0.438 \\
\hline
\end{tabular}

${ }^{*} P$-values $<0.05$ were marked with asterisk

patients [23-25]. Both in primary radiochemotherapy and in surgical approaches, the pretherapeutic haemoglobin level, the number of red blood cells and the need for blood transfusions could be identified as prognostically relevant markers for survival of head and neck cancer patients
[26-28]. Unfortunately, due to the retrospective nature of this analysis, ECOG performance score was not systematically recorded, thus representing a weakness of this study.

Tumor hypoxia in HNSCC is important for predicting treatment outcomes and prognosis. There is evidence 


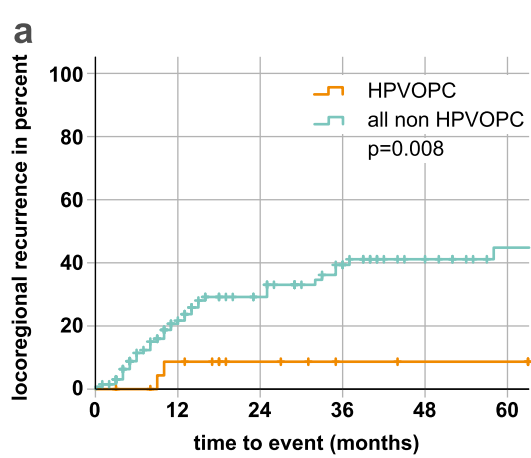

b
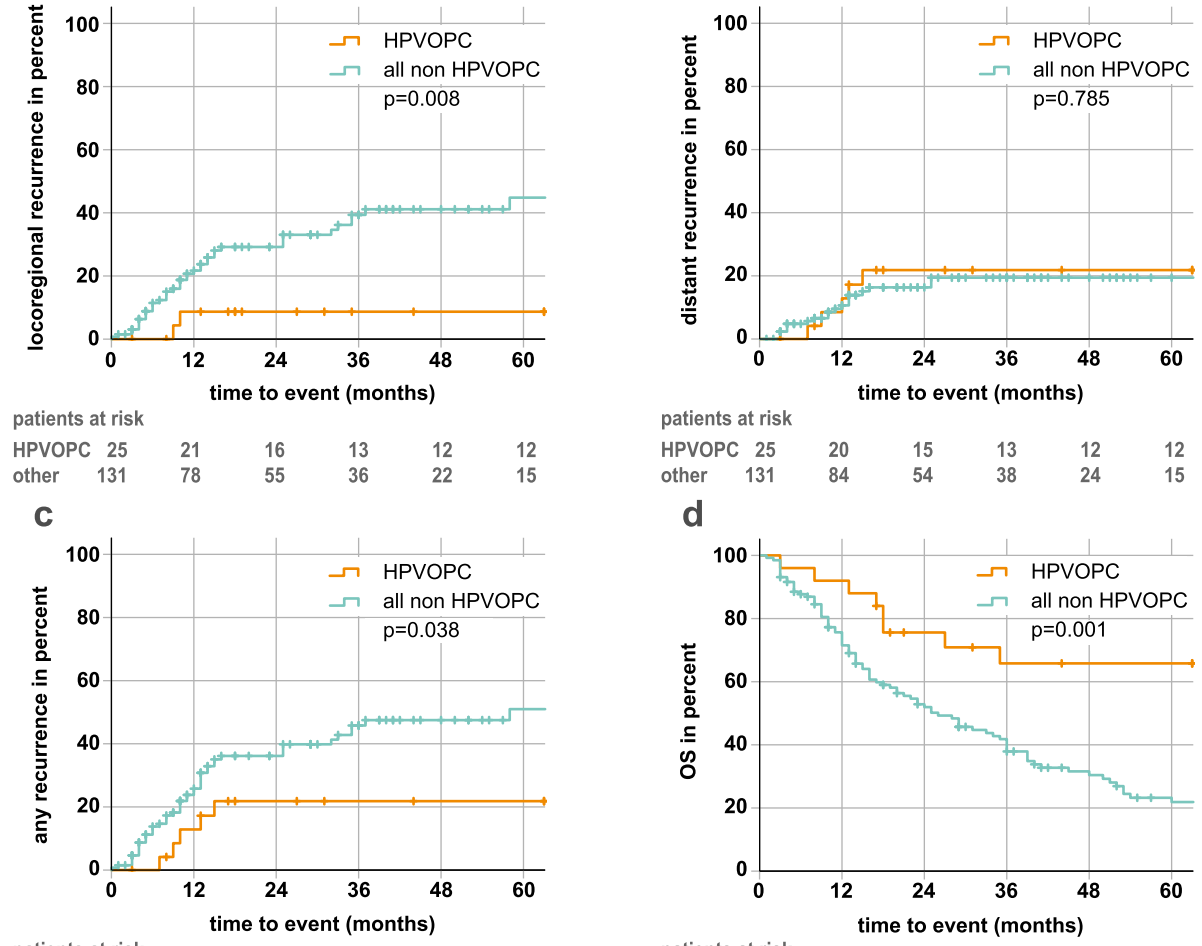

d
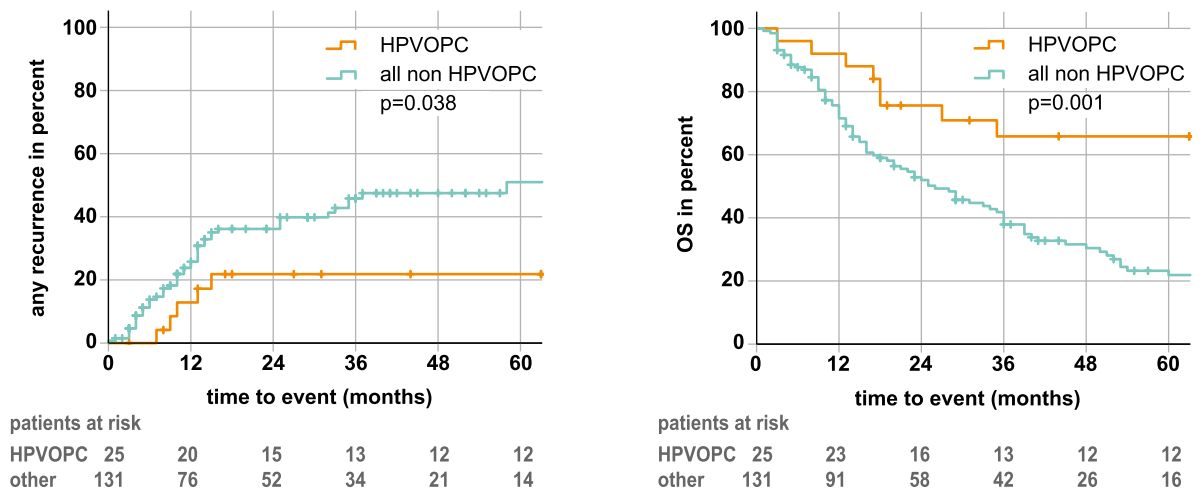

e

f
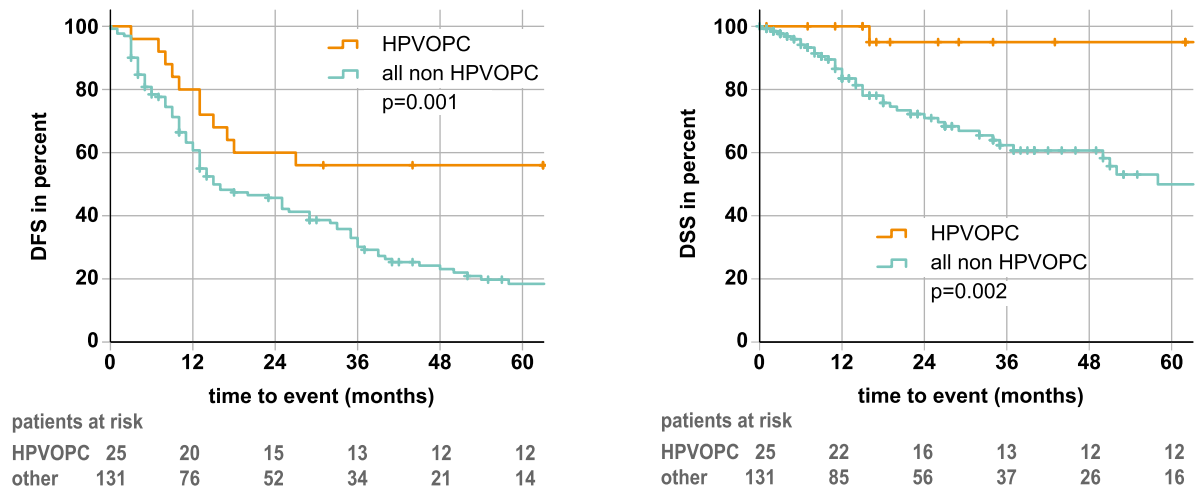

Fig. 3 Kaplan-Meier plots for patients with HPV-p16-positive oropharyngeal cancer (HPVOPC) vs all other patients (non HPVOPC). a locoregional recurrence $\mathbf{b}$ distant recurrence $\mathbf{c}$ any recurrence $\mathbf{d}$ overall survival (OS) and e disease free survival $\mathbf{f}$ disease-specific survival (DSS). $P$-Values (log rank) of the Kaplan-Meier estimates are shown. Follow-up time was clipped at 60 months. Patients at risk are displayed under the respective plots. Censors are represented by crosses

for correlations between prognosis and biomarkers with poor tumor oxygenation such as HIF-1 $\alpha$, GLUT-1 and lactate [29].

The use of genetic markers is increasing. Current studies use a 15-gene signature for the characterization of hypoxia [3]. In a phase III trial patients are treated with the hypoxic radiosensitizer nimorazole in addition to primary chemoradiotherapy to improve the locoregional control rate [30].
HPV-negative HNSCC and HPVOPC are two distinct clinical entities. The genesis is based on different risk factors such as years of exposure to mutagenic noxae (e.g., tobacco and alcohol) or HPV infection. The prognostic value of HPV has been confirmed in many post-hoc analyses of randomized controlled trials [4, 31-34]. This has been taken into account in the latest version of the TNM classification [35]. 
In this study patients with HPVOPC also had a favorable outcome compared to other HNSCC patients (OS $\mathrm{HR}=0.27 ; 95 \%$ KI $0.12-0.59 ; p=0.001$ and DFS HR = 0.37 ; $95 \%$ KI $0.19-0.71 ; p=0.003)$. The 5 -year locoregional tumor control of $91.2 \%$ and the DSS of $95.0 \%$ represent the basis for discussion whether a de-escalation of the therapy is possible in order to reduce side effects without compromising the good prognosis.

In this context, different strategies could be considered: firstly, replacing cisplatin by a less toxic substance in systemic therapy; secondly, decreasing the radiation therapy dose. This could also be done in combination with induction chemotherapy to evaluate the response and differentiate between patients with good and bad prognosis.

Unfortunately, the first approach has failed so far in two recently published phase III trials $[36,37]$. The DeESCALaTE study randomly assigned HPVOPC patients to receive radiotherapy ( $70 \mathrm{~Gy}$ in 35 fractions within 7 weeks) with either cisplatin $(100 \mathrm{mg} / \mathrm{m} 2$ on days 1,22 , 43) or cetuximab $(400 \mathrm{mg} / \mathrm{m} 2$ loading dose followed by $250 \mathrm{mg} / \mathrm{m} 2$ weekly). Acute and late toxicity did not differ significantly between treatment groups at 24 months. However, a significant difference between cisplatin and cetuximab in 2-year overall survival (97.5\% vs $89.4 \%$ ) and 2 -year any recurrence $(6.0 \%$ vs $16.1 \%)$ was seen [36]. The RTOG1016 had the same treatment approach except for the acceleration of radiotherapy (70 Gy in 35 fractions within 6 weeks). Proportions of acute and late moderate to severe toxicity were similar between the cetuximab and cisplatin groups. Estimated 5-year overall survival was significantly lower and locoregional failure significantly higher in the cetuximab group compared to the cisplatin group (5-years OS $77.9 \%$ vs $84.6 \%$; 5 -years LRF $17.3 \%$ vs 9.9\%) [37]. Another phase III randomized trial (TROG 12.01) treating patients with radiotherapy (70Gy in 35 fractions within 7 weeks) and cisplatin $\left(40 \mathrm{mg} / \mathrm{m}^{2}\right.$ weekly) or cetuximab is still ongoing.

For the second approach (reduction of radiation dose) there are a number of heterogeneous studies with partly promising results. In a phase III trial 200 patients were randomly assigned to either receive $50 \mathrm{~Gy}$ or $40 \mathrm{~Gy}$ only to the elective radiation volumes [38]. The trial included all HNSCC irrespective of HPV status. The primary endpoint was dysphagia. In the 40 Gy group a trend was observed toward less dysphagia at 6 months and less moderate salivary gland toxicity without significant differences in disease control (locoregional failure rates $24 \%$ vs $15 \%, p=$ 0.14 ) or survival (OS 72 and $73 \% p=0.73$ ). However, the results for disease control should be considered with caution as this was not a non-inferiority analysis with a sufficient number of patients.

Several other trials used a combination of induction chemotherapy and radiation dose reduction. The favorable results showed survival rates above $90 \%$. In addition to the clinical and radiological interim evaluation of the tumor's therapeutic response as a surrogate for biological aggressiveness and resistance to cytotoxic therapies, induction chemotherapy in theory also offers the possibility of eliminating distant micrometastases. In our cohort $21.8 \%$ of HPVOPC patients had distant metastasis at 2 years. Due to salvage options this did not influence disease specific survival.

The OPTIMA phase II trial stratified patients into a low risk and a high risk group depending on tumor size and lymph node involvement [39]. After 3 cycles of carboplatin and Nab-paclitaxel, the patients were assigned to three treatment arms depending on the radiological assessment of the response. At radiological response rates $<30 \%, 30-50 \%$, or $>50 \%$, low-risk patients received $45 \mathrm{~Gy}, 30 \mathrm{~Gy}$ or no radiotherapy on elective volume and $75 \mathrm{~Gy}, 75 \mathrm{~Gy}$ or $50 \mathrm{~Gy}$ on macroscopic tumor. At a response rate of $<50 \%$ or $>50 \%$, high-risk patients were treated with $45 \mathrm{~Gy}$ or $30 \mathrm{~Gy}$ in elective volume and generally 75 Gy on macroscopic tumor. The 2-years OS and PFS were both $100 \%$ for low risk and 97.0 and $92.2 \%$ for high risk group. In another phase II trial (ECOG 1308) using induction chemotherapy (3 cycles of cisplatin, paclitaxel, cetuximab) followed by reduced-dose radiation (54 Gy in 26 fractions) and weekly cetuximab clinical responders with low risk features (non-T4, non-N2c, $<10 P Y$ ) had a 2-years PFS and OS of 96 and 96\% [40].

The phase III Quarterback Trial comparing standard (70 Gy) versus low dose ( $56 \mathrm{~Gy}$ ) with weekly cetuximab plus carboplatin or carboplatin only, depending on the response to induction chemotherapy ( 3 cycles of TPF) is still ongoing.

Outside of clinical trials, a de-escalation of the therapy of HPVOPC cannot be recommended. At present, platin-based fully dosed dCRT remains the treatment standard. Compared to the postoperative cohort (surgery and adjuvant chemoradiotherapy) of our clinic, dCRT alone resulted in comparable locoregional tumor control rates for HPVOPC (3-year locoregional failure 4.6\% vs $8.7 \%$ [41]. A resection of locoregionally advanced HPVOPC with the consequence of significant functional impairment should remain the exception due to the excellent results of dCRT [42].

\section{Conclusion}

Overall, the presented monocentric cohort containing "everyday patients" treated with dCRT, confirms the known risk factors previously described with robust clinical data. Thus, it is in line with the results of published cohorts. Further translational research based on this dCRT HNSCC cohort is already ongoing within the framework of the clinical cooperation group "Personalized Radiotherapy for Head and Neck Cancer”. 


\section{Acknowledgements}

The authors want to thank all clinical co-workers for their valuable contribution to the KKG dataset.

\section{Authors' contributions}

LS, CM, SM and PB collected clinical data, TK provided the access to pathological data and specimen. PB and SR collected specimen for further analysis. JH, KS and AW analyzed the specimen and performed additional HPV p16 staining. LS wrote the manuscript with the help of $\mathrm{CM}, J \mathrm{H}, \mathrm{KS}, \mathrm{UG}$ and $C B . H Z, C B$ and UG supervised the project; All authors provided critical feedback and helped shape the manuscript. All authors read and approved the final manuscript.

\section{Funding}

Clinical Cooperation Group "Personalized Radiotherapy in Head and Neck Cancer".

\section{Availability of data and materials}

The datasets generated and/or analyzed during the current study are not publicly available due to privacy regulations in the ethics approval but are available from the corresponding author on reasonable request.

\section{Ethics approval and consent to participate}

For data analysis and the retrospective analysis of HPV p16 in some of the patients an ethics approval and consent were obtained (Ethics committee of the medical faculty of the LMU Munich. 448-13; 459-13; 17-116).

\section{Consent for publication}

Not applicable.

\section{Competing interests}

The authors declare that they have no competing interests.

\section{Author details}

${ }^{1}$ Clinical Cooperation Group 'Personalized Radiotherapy in Head and Neck Cancer', Helmholtz Zentrum München, German Research Center for Environmental Health $\mathrm{GmbH}, 85764$ Neuherberg, Germany. ${ }^{2}$ Department of Radiation Oncology, University Hospital, LMU Munich, Marchioninistr 15, 81377 Munich, Germany. ${ }^{3}$ Research Unit Radiation Cytogenetics, Helmholtz Zentrum München, German Research Center for Environmental Health $\mathrm{GmbH}, 85764$ Neuherberg, Germany. ${ }^{4}$ Institute of Pathology, Faculty of Medicine, LMU Munich, Marchioninistr 27, 81377 Munich, Germany. ${ }^{5}$ Research Unit Analytical Pathology, Helmholtz Zentrum München, German Research Center for Environmental Health GmbH, 85764 Neuherberg, Germany. ${ }^{6}$ Department of Otorhinolaryngology, Head and Neck Surgery, University Hospital, LMU Munich, Marchioninistr 15, 81377 Munich, Germany. 7 Department of Radiation Oncology, University of Innsbruck, Anichstraße 35, 6020 Innsbruck, Austria.

Received: 11 September 2019 Accepted: 23 December 2019 Published online: 06 January 2020

\section{References}

1. Ferlay J, Colombet M, Soerjomataram I, Mathers C, Parkin DM, Piñeros M, et al. Estimating the global cancer incidence and mortality in 2018: GLOBOCAN sources and methods. Int J Cancer. 2019;144:1941-53.

2. Blanchard P, Baujat B, Holostenco V, Bourredjem A, Baey C, Bourhis J, et al. Meta-analysis of chemotherapy in head and neck cancer (MACH-NC): a comprehensive analysis by tumour site. Radiother Oncol Elsevier Ireland Ltd. 2011;100:33-40.

3. Linge A, Lohaus F, Löck S, Nowak A, Gudziol V, Valentini C, et al. HPV status, cancer stem cell marker expression, hypoxia gene signatures and tumour volume identify good prognosis subgroups in patients with HNSCC after primary radiochemotherapy: a multicentre retrospective study of the German Cancer consortium radiation. Radiother Oncol. Elsevier Ireland Ltd. 2016;121:364-73

4. Lassen P, Lacas B, Pignon J-P, Trotti A, Zackrisson B, Zhang Q, et al. Prognostic impact of HPV-associated p16-expression and smoking status on outcomes following radiotherapy for oropharyngeal cancer: The MARCHHPV project. Radiother Oncol. Elsevier B.V. 2018;126:107-15.
5. Maasland DH, van den Brandt PA, Kremer B, Goldbohm RA, Schouten LJ. Alcohol consumption, cigarette smoking and the risk of subtypes of headneck cancer: results from the Netherlands cohort study. BMC Cancer. 2014; 14:187.

6. Summerer I, Unger K, Braselmann H, Schuettrumpf L, Maihoefer $C$, Baumeister $\mathrm{P}$, et al. Circulating microRNAs as prognostic therapy biomarkers in head and neck cancer patients. Br J Cancer. 2015;113:76-82.

7. Wintergerst $L$, Selmansberger $M$, Maihoefer $C$, Schüttrumpf $L$, Walch $A$, Wilke C, et al. A prognostic mRNA expression signature of four $16 q 24.3$ genes in radio(chemo)therapy-treated head and neck squamous cell carcinoma (HNSCC). Mol Oncol. 2018;12:2085-101.

8. Baumeister P, Hollmann A, Kitz J, Afthonidou A, Simon F, Shakhtour J, et al. High expression of EpCAM and Sox2 is a positive prognosticator of clinical outcome for head and neck carcinoma. Sci Rep. 2018;8:14582.

9. Hess J, Unger K, Maihoefer C, Schüttrumpf L, Wintergerst L, Heider T, et al. A five-MicroRNA signature predicts survival and disease control of patients with head and neck Cancer negative for HPV infection. Clin Cancer Res. 2019;25:1505-16.

10. Vlacich G, Stavas MJ, Pendyala P, Chen SC, Shyr Y, Cmelak AJ. A comparative analysis between sequential boost and integrated boost intensity-modulated radiation therapy with concurrent chemotherapy for locally-advanced head and neck cancer. Radiat Oncol Radiation Oncology. 2017;12:1-9.

11. Budach W, Bölke E, Kammers K, Gerber PA, Orth K, Gripp S, et al. Induction chemotherapy followed by concurrent radio-chemotherapy versus concurrent radio-chemotherapy alone as treatment of locally advanced squamous cell carcinoma of the head and neck (HNSCC): a meta-analysis of randomized trials. Radiother Oncol. 2016:118:238-43.

12. Bourhis J, Sire C, Graff P, Grégoire V, Maingon P, Calais G, et al. Concomitant chemoradiotherapy versus acceleration of radiotherapy with or without concomitant chemotherapy in locally advanced head and neck carcinoma (GORTEC 99-02): an open-label phase 3 randomised trial. Lancet Oncol. 2012;13:145-53.

13. Matuschek C, Haussmann J, Bölke E, Gripp S, Schuler PJ, Tamaskovics B, et al. Accelerated vs. conventionally fractionated adjuvant radiotherapy in high-risk head and neck cancer: a meta-analysis. Radiat Oncol. 2018;13:195.

14. Adelstein DJ, Li Y, Adams GL, Wagner H, Kish JA, Ensley JF, et al. An intergroup phase III comparison of standard radiation therapy and two schedules of concurrent Chemoradiotherapy in patients with Unresectable squamous cell head and neck Cancer. J Clin Oncol. 2003;21:92-8.

15. Budach V, Stuschke M, Budach W, Baumann M, Geismar D, Grabenbauer G, et al. Hyperfractionated accelerated Chemoradiation with concurrent fluorouracil-Mitomycin is more effective than dose-escalated Hyperfractionated accelerated radiation therapy alone in locally advanced head and neck Cancer: final results of the radiotherapy coo. J Clin Oncol. 2005;23:1125-35.

16. Budach V, Stromberger C, Poettgen C, Baumann M, Budach W, Grabenbauer G, et al. Hyperfractionated Accelerated Radiation Therapy (HART) of 70.6 Gy With Concurrent 5-FU/Mitomycin C Is Superior to HART of 77.6 Gy Alone in Locally Advanced Head and Neck Cancer: Long-term Results of the ARO 95-06 Randomized Phase III Trial. Int J Radiat Oncol. Elsevier Inc. 2015:91:916-24.

17. Pignon J-P, le Maître A, Maillard E, Bourhis J. Meta-analysis of chemotherapy in head and neck cancer (MACH-NC): an update on 93 randomised trials and 17,346 patients. Radiother Oncol. Elsevier Ireland Ltd. 2009;92:4-14.

18. Helfenstein S, Riesterer O, Meier UR, Papachristofilou A, Kasenda B, Pless M, et al. 3-weekly or weekly cisplatin concurrently with radiotherapy for patients with squamous cell carcinoma of the head and neck - a multicentre, retrospective analysis. Radiat Oncol. 2019;14:32.

19. Carpén T, Saarilahti K, Haglund C, Markkola A, Tarkkanen J, Hagström J, et al. Tumor volume as a prognostic marker in p16-positive and p16-negative oropharyngeal cancer patients treated with definitive intensity-modulated radiotherapy. Strahlentherapie und Onkol. 2018;194:759-70.

20. Oosterkamp S, de Jong JMA, Van Den Ende PL, Manni JJ, Dehing-Oberije C, Kremer B. Predictive value of lymph node metastases and Extracapsular extension for the risk of distant metastases in laryngeal carcinoma. Laryngoscope. 2006;116:2067-70.

21. Suzuki H, Matoba T, Hanai N, Nishikawa D, Fukuda Y, Koide Y, et al. Lymph node ratio predicts survival in hypopharyngeal cancer with positive lymph node metastasis. Eur Arch Otorhinolaryngol. 2016;273:4595-600.

22. Chen C-C, Lin J-C, Chen K-W. Lymph node ratio as a prognostic factor in head and neck cancer patients. Radiat Oncol. 2015;10:181. 
23. Dicato M, Plawny L, Diederich M. Anemia in cancer. Ann Oncol. 2010;21: vii167-72.

24. Leifert AJ. Anaemia and cigarette smoking. Int J Lab Hematol. 2008;30:177-84

25. Jager-Wittenaar H, Dijkstra PU, Dijkstra G, Bijzet J, Langendijk JA, van der Laan B, et al. High prevalence of cachexia in newly diagnosed head and neck cancer patients: an exploratory study. Nutrition Elsevier Ltd. 2017;35:114-8

26. Ghadjar P, Pöttgen C, Joos D, Hayoz S, Baumann M, Bodis S, et al. Haemoglobin and creatinine values as prognostic factors for outcome of concurrent radiochemotherapy in locally advanced head and neck cancers. Strahlentherapie und Onkol. 2016;192:552-60.

27. Baumeister $\mathbf{P}$, Canis $M$, Reiter M. Preoperative anemia and perioperative blood transfusion in head and neck squamous cell carcinoma. PLoS One. 2018;13:e0205712 Goubran H, editor.

28. Danan D, Smolkin ME, Varhegyi NE, Bakos SR, Jameson MJ, Shonka DC. Impact of blood transfusions on patients with head and neck cancer undergoing free tissue transfer. Laryngoscope. 2015;125:86-91.

29. Bredell MG, Ernst J, El-Kochairi I, Dahlem Y, Ikenberg K, Schumann DM. Current relevance of hypoxia in head and neck cancer. Oncotarget. 2016;7:50781-804.

30. Christiaens M, Collette S, Overgaard J, Gregoire V, Kazmierska J, Castadot P, et al. Quality assurance of radiotherapy in the ongoing EORTC 1219DAHANCA-29 trial for HPV/p16 negative squamous cell carcinoma of the head and neck: Results of the benchmark case procedure. Radiother Oncol. 2017;123:424-30 Elsevier B.V.

31. Vermorken JB, Stöhlmacher-Williams J, Davidenko I, Licitra L, Winquist E, Villanueva C, et al. Cisplatin and fluorouracil with or without panitumumab in patients with recurrent or metastatic squamous-cell carcinoma of the head and neck (SPECTRUM): an open-label phase 3 randomised trial. Lancet Oncol. 2013;14:697-710.

32. Vermorken JB, Mesia R, Rivera F, Remenar E, Kawecki A, Rottey S, et al. Platinum-based chemotherapy plus Cetuximab in head and neck Cancer. N Engl J Med. 2008:359:1116-27.

33. Rosenthal DI, Harari PM, Giralt J, Bell D, Raben D, Liu J, et al. Association of Human Papillomavirus and p16 status with outcomes in the IMCL-9815 phase III registration trial for patients with Locoregionally advanced Oropharyngeal squamous cell carcinoma of the head and neck treated with radiotherapy with or without C. J Clin Oncol. 2016;34:1300-8.

34. Ang KK, Zhang Q, Rosenthal DI, Nguyen-Tan PF, Sherman EJ, Weber RS, et al. Randomized phase III trial of concurrent accelerated radiation plus Cisplatin with or without Cetuximab for stage III to IV head and neck carcinoma: RTOG 0522. J Clin Oncol. 2014;32:2940-50.

35. Huang SH, O'Sullivan B. Overview of the 8th Edition TNM Classification for Head and Neck Cancer. Curr Treat Options in Oncol. 2017;18:40.

36. Mehanna H, Robinson M, Hartley A, Kong A, Foran B, Fulton-Lieuw T, et al. Radiotherapy plus cisplatin or cetuximab in low-risk human papillomavirus-positive oropharyngeal cancer (De-ESCALaTE HPV): an open-label randomised controlled phase 3 trial. Lancet. 2018;0:5-7 Available from: https://linkinghub.elsevier.com/retrieve/pii/S014067361 8327521.

37. Gillison ML, Trotti AM, Harris J, Eisbruch A, Harari PM, Adelstein DJ, et al. Radiotherapy plus cetuximab or cisplatin in human papillomavirus-positive oropharyngeal cancer (NRG oncology RTOG 1016): a randomised, multicentre, non-inferiority trial. Lancet. 2018;0:1-11 Available from: https:// linkinghub.elsevier.com/retrieve/pii/S014067361832779X.

38. Nevens D, Duprez F, Daisne JF, Dok R, Belmans A, Voordeckers M, et al. Reduction of the dose of radiotherapy to the elective neck in head and neck squamous cell carcinoma; a randomized clinical trial. Effect on late toxicity and tumor control. Radiother Oncol. 2017;122:171-7.

39. Seiwert T. OPTIMA: a phase II dose and volume de-escalation trial for human papillomavirus-positive oropharyngeal cancer. Ann Oncol. 2019; 30(10):1673

40. Marur S, Li S, Cmelak AJ, Gillison ML, Zhao WJ, Ferris RL, et al. E1308: phase II trial of induction chemotherapy followed by reduced-dose radiation and weekly Cetuximab in patients with HPV-associated Resectable squamous cell carcinoma of the oropharynx - ECOG-ACRIN Cancer research group. J Clin Oncol. 2017:35:490-7.

41. Maihoefer C, Schüttrumpf L, Macht C, Pflugradt U, Hess J, Schneider L, et al. Postoperative (chemo) radiation in patients with squamous cell cancers of the head and neck - clinical results from the cohort of the clinical cooperation group "Personalized Radiotherapy in Head and Neck Cancer". Radiat Oncol. 2018;13:123.

42. Nichols AC, Theurer J, Prisman E, Read N, Berthelet E, Tran E, et al. Radiotherapy versus transoral robotic surgery and neck dissection for oropharyngeal squamous cell carcinoma (ORATOR): an open-label, phase 2, randomised trial. Lancet Oncol Elsevier Ltd. 2019;20:1349-59.

\section{Publisher's Note}

Springer Nature remains neutral with regard to jurisdictional claims in published maps and institutional affiliations.
Ready to submit your research? Choose BMC and benefit from:

- fast, convenient online submission

- thorough peer review by experienced researchers in your field

- rapid publication on acceptance

- support for research data, including large and complex data types

- gold Open Access which fosters wider collaboration and increased citations

- maximum visibility for your research: over $100 \mathrm{M}$ website views per year

At BMC, research is always in progress.

Learn more biomedcentral.com/submissions 